\title{
The Effect of Ketogenic-Diet on Health
}

\author{
Amal Alharbi', Noorah Saleh Al-Sowayan ${ }^{2 *}$ \\ ${ }^{1}$ Master Student in Biology Department, College of Science, Qassim University, Buraydah, KSA \\ ${ }^{2}$ Department of Biology, Faculty of Science, Qassim University, Buraydah, KSA \\ Email: ^nsaoiean@qu.edu.sa, *knaaj1@yahoo.com
}

How to cite this paper: Alharbi, A. and Al-Sowayan, N.S. (2020) The Effect of Ketogenic-Diet on Health. Food and Nutrition Sciences, 11, 301-313. https://doi.org/10.4236/fns.2020.114022

Received: March 28, 2020

Accepted: April 20, 2020

Published: April 23, 2020

Copyright (C) 2020 by author(s) and Scientific Research Publishing Inc. This work is licensed under the Creative Commons Attribution International License (CC BY 4.0)

http://creativecommons.org/licenses/by/4.0/ (c) (i) Open Access

\begin{abstract}
In recent years, the ketogenic diet is the most popular diet around the world. Therefore, keto diet, short for ketogenic, involves eating a high amount of fat, a moderate amount of protein and very few carbs. This research paper aims to know about the effect of a ketogenic diet on our body, to know about the mechanism of the ketogenic diet in treating neurodegenerative disorders and to know about the mechanism of the ketogenic diet in reducing the weight of our body. Also, the objective was to investigate the ketogenic diet stimulates ketogenesis which treats certain neurodegenerative disorders. Although this is high fats containing food it is beneficial for our body in certain conditions. It is also useful in the conditions in which the brain requires a low level of glucose so the brain starts utilizing ketone bodies. As the intake of carbohydrates is lowered so it is also used to reduce the weight of the body. In this research, the qualitative methodology has been adopted which refers to secondary sources of data. In this project, I used a variety of research that has also been undertaken by numerous researchers including dietitians who tend to support the positive benefits of using ketogenic diets to manage losing weight as well as other health problems that could result from overweight. Also, we used a table to show the difference between studies. Finally, it is important to note that the ketogenic-diet has created debate, partially although traditional dietary education has, for years, illustrated the adverse effects of high overall including trans-fat intake.
\end{abstract}

\section{Keywords}

The Keto Diet, Fats, Carbohydrates, Ketosis

\section{Introduction}

The keto-diet which is also known as the ketogenic diet is a specific type of diet in which low carbohydrates are taken but the content of fats and proteins is kept high in food. So the body's weight is reduced with high fats. This way of dieting 
has also been in process for several years and it increases the biochemical effect of fasting. As the intake of carbohydrates is reduced so the body is forced to switch to fatty acid oxidation. So ketogenesis occurs in the body and a sufficient number of calories are left in our body for normal daily activity. As it stimulates oxidation and ketogenesis so due to its benefits now it is also used to treat different disorders such as refractory epilepsy, Parkinson's diseases, Alzheimer's disease, traumatic brain injury, and amyotrophic lateral sclerosis. Although there are more benefits of ketogenic-diet a decrease in bone density is marked side effect of ketogenic-diet which then leads to osteoporosis [1].

As in this type of dieting, calories are restricted so it also gives benefit by reducing the risk of different diseases. The intake of low carbohydrate-containing food changes the body's metabolism thus initiating fatty acid oxidation. So it also increases the life span of the person [2]. Attention deficit hyperactivity disorder is commonly found disorder in children, adults, and adolescents. In this type of disorder, inattentiveness occurs and the person fails to focus properly due to lack of attention. Many studies have been conducted but still, the cause of this disease is unknown but it is considered as inherited disorder. So different studies have been conducted and it has been found that the ketogenic diet is effective in treating this disorder. Similarly, it is also effective in reducing seizures but the actual mechanism by which it reduces seizures is unknown. When human intakes low levels of carbohydrates, our brain starts utilizing ketone bodies instead of glucose. So this is the mechanism behind the reduction of seizures [3].

As ketogenesis occurs in this mechanism so keto bodies are produced as a result and keto bodies are best alternates for the body as energy fuel. Because glucose is produced by the metabolism of carbohydrates and in this diet intake of carbohydrates is reduced. So the body starts utilizing keto bodies as fuel and ATPs (which are energy packets for our body) are produced by B-hydroxybutyrate. The sequencing of single-cell RNA occurs in adipose tissue so gamma and $\mathrm{T}$ cells become active and reduce inflammation in adipose tissue. So in this way, inflammation does not occur in adipose tissue due to an increase in the mechanism of ketogenesis [4].

AIMS:

- To know about the effect of a ketogenic diet on our body.

- To know about the mechanism of the ketogenic diet in treating neurodegenerative disorders.

- To know about the mechanism of the ketogenic diet in reducing the weight of our body.

Objectives:

Ketogenic diet stimulates ketogenesis which treats certain neurodegenerative disorders. Although this is high fats containing food it is beneficial for our body in certain conditions. It is also useful in the conditions in which the brain requires a low level of glucose so the brain starts utilizing ketone bodies. As the intake of carbohydrates is lowered so it is also used to reduce the weight of the body. 


\section{Literature Review}

The ketogenic-diet based on a ketogenic cycle as well as includes low starch, milk protein, as well as ketogenic diet. Ketosis is a biochemical cycle wherein proteins are depleted of carbohydrate intake, the body's primary supply of sugar, as a consequence, deposits of accumulated fat are decomposed to compounds named ketones [5]. When there is a limit on carbs throughout the system, the fat is decomposed by the stomach, cellulose, as well as lipids. The liver utilizes 2 pathways to feed the bodies, namely ketogenesis as well as gluconeogenesis. For ketogenic degradation, the human diet consists of around 70 percent carbohydrate, 25 percent protein, with 5 percent carbohydrate [6]. After a human achieves ketosis, several cells could use ketone systems to create energy before the person continues to consume carbohydrates now. When an adult enters the phase of ketosis, they may continue to enjoy the health advantages that come with any of it.

Recent research has shown [7] expresses few indications of ketosis health effects are the defense and development of the nervous system, enhancement of mitochondrial development, ketones serving as antioxidants as well as contributing to encouraging the growth of certain cancers. Most people eat a high-carb diet, and the body uses sugar for food. There have been glucose issues [8]. The body will store around two-thousand calories of glucose storage at any period throughout the type of glucose. The transition from the use of circulating glucose to the breakdown of accumulated fat as an energy source typically occurs over 3 to 4 days of consuming less than 40 or Fifty grams of carbohydrates each day [9]. The amount of readily digestible carbohydrates is decreased whereas the calorie intake of protein and fat is increased.

[10] claimed ketogenic-diet is a quite challenging plan to pursue owing to the reality that almost all American products are very rich in refined starches (UNM). But by exercising as well as knowing whatever the diet seeks to accomplish, it can be simplified to a predictable regimen (UNM). There are 4 ways that people consider ketogenic-diet challenging. The first explanation is the stock, buying food in the grocery store can be rather difficult, as to purchase something that will be lower in carbohydrate, or you'll get a rise out of keto [11]. The second possibility is that for this diet to succeed, one needs to be careful about self-control, so it's quite simple to also be influenced. The third explanation is to gain experience of the ketogenic, which would give us a broader understanding of nutrition [4]. The 4th factor is how it requires time and dedication to reveal the result, but sadly don't have the time or patience. Dr. Russel was the founder of a ketogenic diet which was used to help eliminate obesity. In 1922, he developed a diet at the Cleveland Clinic to treat diseases, particularly children of Epilepsy. "In almost a couple of years [12], ketogenic-diet has maintained a role throughout the medical profession as a preventive diet for childhood epilepsy and it has been commonly used since its use has stopped with the advent of antiepileptic substances". 
Currently [14], with dietary developments, the revival of ketogenic-diet as a recipe for dramatic weight loss is a fairly recent thing that has been proven to be very successful, at least initially as shown in Figure 1. The ketogenic-diet was first "designed for the diagnosis of childhood epilepsy throughout the 1930s and it has been commonly used over the past few decades, but has diminished in prevalence since the advent of successful anticonvulsant medications". Latest work over the past few years or more has been carried out proof of the therapeutic efficacy of keto in multiple medical disorders, including asthma, polycystic ovarian disorder, obesity, neurological issues, Alzheimer, as well as the reduction in chronic diseases for respiratory and heart disease [15]. Different studies have been conducted in the past to know about the effect of a ketogenic diet on our body. A study was conducted at the University of Toronto in which the activity level of the ketogenic diet was compared with the control diet. So two groups of the ketogenic diet were made and food was given in order of 3:1 parts, the highest ratio was consisting of fats and the lowest was consists of proteins. While a balanced diet was given to another group of rats [3]. Another study was conducted on mice in which the tolerance level of mice was determined when they fed on high fat-containing food. The results showed that the weight of mice was not increased despite high fats containing food. If this food was given for more time so it also reduced the weight of mice and at some point it also maintained the weight of mice. In another group, the effect of ketogenic-diet was observed on obesity. So firstly the mice were given an HF diet and then they were shifted to keto diet so it caused a rapid decrease in weight [16].

In another study, the effect of ketogenic-diet was observed on skeletal muscles. This study was conducted on two groups of young and old rats. The food was given to rats for almost 4 weeks and the calories of this food were increased gradually. It has been found that ketones level was increased in the blood in adult rats as compared to old rats. Similarly, mitochondrial respiration was increased

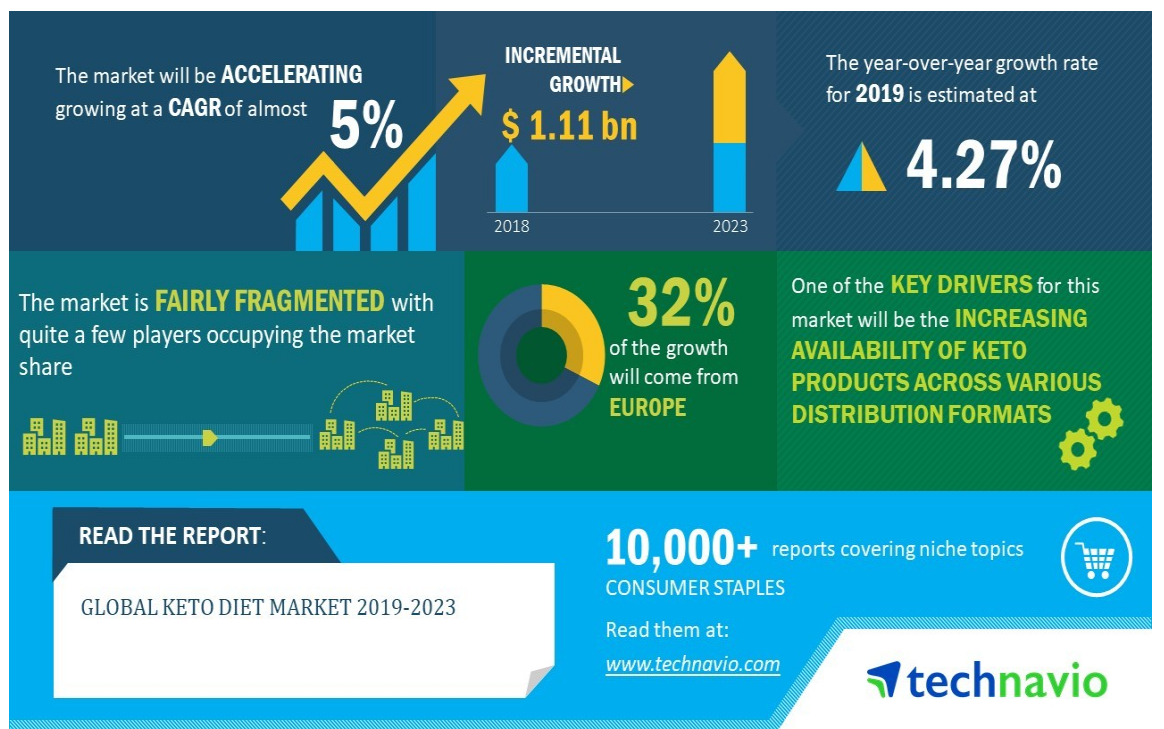

Figure 1. Global data of keto diet market source [13]. 
in young rats as compared to old rats. So there was a marked decrease in weight in young rats. Old rats were resistant to all of the changes in the body except for weight loss. So it showed that ketogenic-diet is safe for old age too [17]. The effect of food is also associated with the psychological condition so a study was conducted to know about this fact. Four different dietary meals [16] such as carbohydrates, proteins, vitamins, and ketogenic diet were made and the food was given to different groups of mice. The effect of rodent ketogenic diet was compared with high fat containing diet. So it has been found that there was a marked increase in the weight of mice which were feeding the ketogenic diet. But the weight of another group of mice was reduced which was feeding on high fats containing food [16].

\subsection{Ketogenic-Diet Is Bad in Long Term}

To describe that the Ketogenic diet is harmful in the long run needs to consider how the Ketogenic-diet functions. A Ketogenic diet is one that is very light in sugar and is one of the key sources of nutrition for the organism. Through ingestion, the body converts down calories high in fat and releases glucose, used as a primary source of energy for all the body to work. Once the system is depleted of sugar, it changes the food supply from sugar to fat as well as ketones. Each phase is recognized as ketosis, in which the system depends on fat as well as ketones because of its key power source. The body normally reaches such a condition within 4 to 5 days after commencing a diet [11].

As per [10] such dietary transition is usually followed by numerous symptoms including drowsiness, fatigue, concentration issues, nausea, poor breathing, abdominal pain, trouble sleeping, indigestion, depression, and few others. For all this purpose, such effects are sometimes referred to as Keto Flu. Usually, the effects of Keto Flu go down for a week, as well as the body starts to lose fat. The dramatic weight loss will also be very noticeable and drastic. However, most individuals would be very glad about seeing dietary work. Yet these can come with some adverse consequences that may be unpleasant or maybe even harmful to the well-being/health. Acknowledge that the body requires a nutritious diet for a healthy diet. So to extract your body from other healthy food types, a disparity is produced in the system that would contribute to health problems. If the body tends to suffer a lengthy-term nutritional deficit, it may present a variety of threats to the general well-being.

Nutrient shortages could lead to dehydration including hepatic encephalopathy, which is very well known. Ketogenic-diet, therefore, aims to be poor in fibre and nutrients such as calcium, magnesium, potassium and vitamins A, B as well as B6. Furthermore, it ought to increase the consumption of water. To contact a doctor for adequate treatment to help prevent a lengthy variety of health problems that would follow a nutritional deficit. Nevertheless, longevity is still the main issue with this type of diet. When it starves the body of favourite food, the body can begin to crave more, causing to give up the diet. When getting back to 
eating regularly again, the recovery gaining weight may also be drastic. It may be followed by adverse effects too when the body starts to adapt according to glucose as the primary energy source. In all these factors, the Ketogenic-diet shouldn't be used as a lengthy-term weight reduction strategy. To weight loss in a rush for the near term, but are willing to experience painful effects, it will be able to seek the approach. Yet it may be a lot harder to make this diet a sustainable and lengthy-term option for weight loss [1].

\subsection{Effect of a Ketogenic Diet on Our Body}

The ketogenic diet includes adherence to an exceptionally low-carb, big-fat diet to place the body throughout a stable condition called ketosis. It helps the body more effective in burning calories. The ketogenic-diet would certainly result in a decrease of libido as you continue the diet because the body would suffer signs of carb withdrawals including probably keto-flu. Many individuals do learn of keto influenza, which might trigger anytime to start a diet. This is the product of the body transitioning to the low-carbon environment. Decreasing carbohydrate consumption causes the body to use ketones for nutrition rather than glucose. If the organism is now in ketosis - the absorption of fat rather than glucose-the ketogenic diet works.

Significant evidence [4] indicates in figure 3 whether ketogenic-diet prevents seizures in infants, often as successfully as medications. As a result of these neuroprotective properties, concerns were raised regarding the current potential advantages of several other brain diseases including Alzheimer's, Parkinson's disease, sclerosis, sleep problems, or even cancer. Nonetheless, there have been no medical trials to justify the use of ketosis to address such disorders. Weight reduction is the main explanation that patients are using a ketogenic-diet.

Recent research [18] provides strong evidence of a greater weight loss in people on a ketogenic or extremely low caloric intake relative to those on a somewhat more conventional reduced-fat diet or Caribbean diet. Nevertheless, the disparity in losing weight tends to vanish over the period. Ketogenic diets also have been found to boost the regulation of blood glucose in people with form 2 diabetes, at least initially. There is a much more controversial impact on levels of cholesterol. Many tests indicate that certain people have elevated levels of cholesterol at the onset, only to find that cholesterol drop a few weeks later. Moreover, there is no long-term work to examine the impact on diabetes including hypothyroidism over the period.

\subsection{The Mechanism of the Ketogenic Diet in Treating Neurodegenerative Disorders}

Growing amounts of data indicate the importance of ketogenic diets in a host of neurological disorders such as obesity, high cholesterol, including diabetes. Regarding neurological conditions, ketogenic-diet is accepted as a successful therapy for pharma-coexistent schizophrenia, but new evidence indicates that ketogenic-diets could even be helpful in multiple sclerosis, Parkinson's, Alzheimer's 
disease as well as other mitochondrial diseases. Since these disorders have distinct molecular mechanisms and characteristics. Many growing pathways may describe the impact of ketogenic-diet. Such processes are engineered to provide effective energy supply for the diagnosis of several forms of neurodegenerative disorders caused by selective neuro-hypo-metabolism; to mitigate oxidative stress related to various forms of physiological anxiety; to improve endothelial dysfunction processes, and to reap the benefits of the potential of ketones to circumvent the deficiency in complicated I exercise [19].

The ketogenic-diet is a low-carbon and otherwise rich carbohydrate diet. This application has a fasting-like adverse effect that takes the entire body into another phase of ketosis. The ketogenic diet is used for around 10 decades in medication-resistant epilepsy treatment, but recent findings suggest potential neuroprotective properties [19]. To date, only a few research [20] have examined the importance of ketogenic-diet throughout the mitigation of Alzheimer's disease (AD) including Parkinson's disease (PD). Individual experiments of individual volunteers reported a decrease in the effects of the disease following diagnosis. Nevertheless, the introduction of ketogenic-diet to aged individuals poses some questions. Individuals with neurodegenerative disorders are at danger of deficiency, whereas calorie consumption loss is linked with disease effects. The ketogenic-diet, in particular, contributes to decreased appetite; it is not appealing from a nutritive perspective and can be caused by adverse effects of the stomach and intestines. One of which may contribute to a further decrease in the amount of food eaten by old people with neuro-degenerative problems and, as a result, a further decrease in the availability of nutrition given by the food. There are no details given on the lengthy-term use of ketogenic-diet in people with a neurodegenerative illness or on its impact on disease effects. Further work is required to determine the competency of ketogenic-diets in the care of PD or AD-related individuals [21].

\subsection{The Mechanism of Ketogenic-Diet in Reducing the Weight of Our Body}

There is solid evidence of whether ketogenic-diets are quite successful at losing weight. It will make lose weight, maintain muscle mass, and boost other disease indications [15]. Also, several studies contrasted the prescribed low-fat diet with a ketogenic diet for losing weight. Conclusions also suggest that ketogenic-diet is better only through the overall calorie consumption is matched [22]. In one research [18], people on keto lose 2.2 times further fat than that on small-calorie, small-fat diets. The amounts of triglyceride, as well as HDL lipids, have also increased. Typically losing weight outcomes are seen in Figure 2.

A further study [9] contrasted the low-carb diet with the UK Obesity Nutritional guidelines. The minimal-carb category was reported to have lost $15.4 \mathrm{lbs}$ $(6.7 \mathrm{~kg})$, whereas the minimal-fat team has lost just $4.8 \mathrm{lbs}(2.3 \mathrm{~kg})$. The minimum-carb diet produced $3 \mathrm{x}$ additional losing weight throughout 6 weeks [12]. Ketogenic-diets encourage weight loss: 


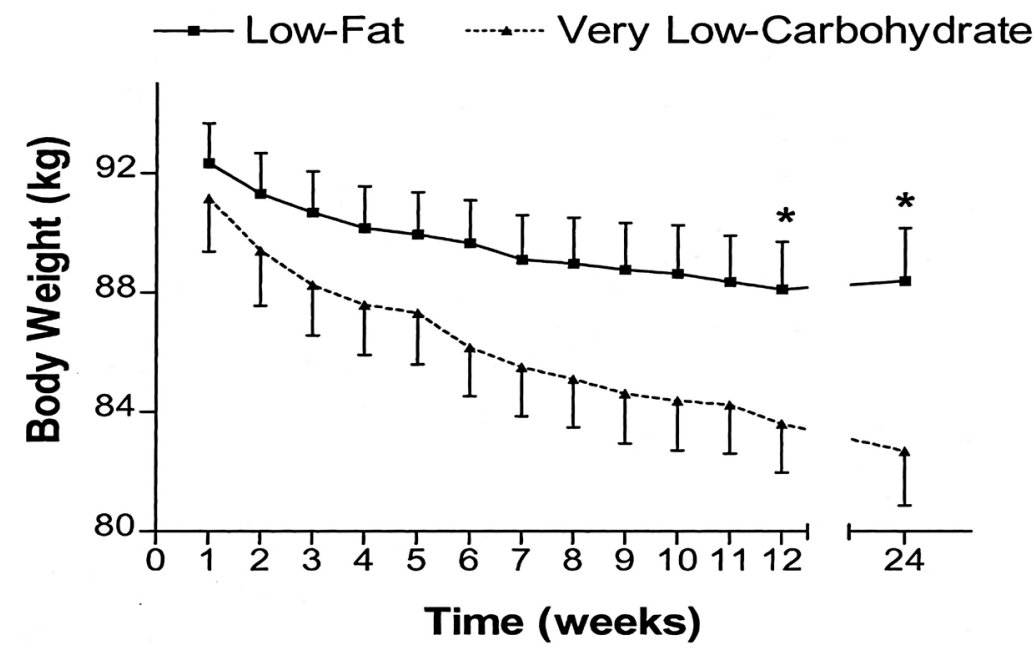

Figure 2. Weight loose mechanism [4].

- Higher protein consumption: certain ketogenic diets contribute to improved protein intake, which has multiple losing weight advantages.

- Removal of carbs: restricting your starch consumption always reduces your dietary choices. It will greatly decrease calorie consumption, which is the secret to weight loss.

- Gluconeogenesis: the system transforms fat as well as proteins into food carbohydrates. The cycle will consume a lot of extra calories every day [23].

- Suppressive craving: ketogenic-diets make you feel complete. It is accompanied by major changes in starvation hormones, namely ghrelin, and leptin [21].

- Increased insulin tolerance: ketogenic-diets can significantly increase insulin resistance, which can greatly improve fuel consumption as well as metabolites [19].

- Reduced-fat maintenance: some research shows [18] that ketogenic-diets can minimize fatty acid oxidation, the process of changing glucose to lipid.

- Improved fat incinerating: ketogenic-diets easily increase the number of fats that consume during rest, everyday life \& workout [24].

\section{Methodology}

A variety of research has also been undertaken by numerous researchers including dietitians who tend to support the positive benefits of using ketogenic diets to manage losing weight as well as other health problems that could result from overweight. Nonetheless, owing to the extreme complexity of the diet, several people never use the ketogenic-diet as a lengthy-term diet. There have been numerous approaches mentioned below that illustrate the study of the ketogenic diet as well as its brief-term effects. In the research on the topic, the qualitative methodology has been adopted it considers secondary sources of data. The data from past literary work, official reports, government websites, as well as researches conducted by NGOs. 


\section{Findings \& Discussion}

Researches [20] [25] has shown that ketogenic-diets generally work only in the short term and could be unhealthful. When the body reaches ketosis, it also tends to lose energy, become incredibly weak, and ultimately go into malnutrition. In reality, it is much harder to lose weight. [22] said that he does not accept the ketogenic-diet induces muscle destruction. He warned that it wasn't ideal for anyone to attempt to accumulate strength. Health support's many specialists surveyed [26] had more words of warning. Ketogenic-diets cannot be used under direct observation as well as for shorter periods not. It could do more harm in the long run. The heart, that is also an organ, can be hurt. [25] who, under limited conditions, used ketogenic-diets on certain cancer sufferers, warned, "People are doing whatever they can to lose weight and keep off. Any of them took the ketogenic diet a notch higher, to use a feeding tube implanted via the nasal into the stomach [23].

Dieters conform to a stringent 900-calorie big-protein, carb-free diet delivered via the pipe via a low-drip recirculation pump. In addition to the low carb diet, only coffee or tea, black coffee or green tea drink is permitted. [6] argued to maintain that the ketogenic-diet is healthy and successful, but for those that want to lose a few kilograms. [16] indicated "It is a stupid solution to losing weight," an already healthy person may have severe complications, such as infectious diseases, whether the pipe becomes infected, elevated sodium content, and could even cause vomiting, constipation, and diarrhoea. Alternatively, anyone planning for marriage should treat themselves properly, partake in a lot of physical exercises, such as cycling, bike riding, or jogging, and then be healthier for themselves by eating healthy, natural, nutrient-dense healthy food. There's no magic solution for lengthy-term losing weight, says [6]. For lengthy-term weight maintenance, a Caribbean-style diet based on vegetables, fruits, balanced grains, peas, fish including vegetable oil that can be safe for existence.

No specific diet is acceptable for all, particularly because personal metabolisms, genetics, body shapes, habits, sense of taste and personal opinions vary. Moreover, ketogenic diets can perform well for overweight and obese people or at threat of coronary heart disease. But, to like high-fats products but enjoy carbohydrates, this diet might be hard for people to adhere to. Ketogenic-diets may be used throughout the near term to help and lose weight and boost health, mood, etc. However, this needs a lot of effort and therefore must be accompanied by eating healthy. Ketogenic-diets could therefore never be the right choice for professional athletes as well as those seeking to create massive quantities of weight. Vegans or vegetarians might also be struggling with such a diet attributable to the primary role provided by livestock, poultry, fish and fruits, and vegetables.

In comparison, the change to a ketogenic-diet may also trigger adverse symptoms sometimes referring to as "keto flu". It can involve reduced energy as well as mental control, decreased appetite, sleeplessness, diarrhoea, intestinal pain, and reduced workout efficiency. Even though this is never the case, it can en- 
courage some people to stop if they get properly started, particularly when the first few weeks of any diet are the hardest. According to the extremely small consumption of carbohydrate-less than 50 - 60 grams each day-ketogenic-diets could therefore never be ideal for those who choose to run off on a holiday [8] Many studies approved that the ketogenic diet has different effects on health, this was shown in Table 1.

Table 1. The effects of the keto diet on health.

\begin{tabular}{|c|c|c|c|c|}
\hline Study & Populations & Intervention/variables & Findings & Comments \\
\hline Murphey, 2005 & $\begin{array}{l}\text { No of groups: } 2 \text {, the } \\
\text { study was conducted } \\
\text { on rats }\end{array}$ & $\begin{array}{l}\text { Control group: ketogenic diet was } \\
\text { given to control group of rats which } \\
\text { contained a high portion of fats } \\
\text { Another group: the other group of } \\
\text { rats was given balanced food }\end{array}$ & $\begin{array}{l}\text { Ketogenic diet decreases animal } \\
\text { activity similarly these also cause } \\
\text { attention deficit disorder in children }\end{array}$ & $\begin{array}{l}\text { This study was conducted on } \\
\text { rats to know about the effect of } \\
\text { the ketogenic diet on rats }\end{array}$ \\
\hline Kennedy, 2007 & $\begin{array}{l}\text { Number of groups: } 2 \text {, } \\
\text { this study was } \\
\text { conducted on rats }\end{array}$ & $\begin{array}{l}\text { Control group: high fats containing } \\
\text { food was given } \\
\text { Another group: a balanced diet was } \\
\text { given }\end{array}$ & $\begin{array}{l}\text { Ketogenic diet decreases the weight } \\
\text { of mice and it also reduced obesity }\end{array}$ & $\begin{array}{l}\text { This study was conducted on } \\
\text { rats to know about the effect of } \\
\text { the ketogenic diet on the weight } \\
\text { of rats }\end{array}$ \\
\hline Duplisea, 2017 & $\begin{array}{l}\text { Number of groups: } 2 \text {, } \\
\text { Separate groups of } \\
\text { Young and old rats, } \\
\text { food was given for } 4 \\
\text { weeks }\end{array}$ & $\begin{array}{l}\text { The effect of the ketogenic diet was } \\
\text { observed on young and old rats }\end{array}$ & $\begin{array}{l}\text { There was observed a marked } \\
\text { decrease in the weight of young rats } \\
\text { and ketones levels were increased in } \\
\text { young rats. While in old rats only } \\
\text { weight loss was observed while they } \\
\text { were resistant to other changes in } \\
\text { body }\end{array}$ & $\begin{array}{l}\text { This study was conducted on } \\
\text { young and old rats and effect of } \\
\text { fame type of food was observed } \\
\text { on both types of groups }\end{array}$ \\
\hline Kennedy, 2007 & $\begin{array}{l}\text { Different groups of } \\
\text { mice were made }\end{array}$ & $\begin{array}{l}\text { The effect of high fats containing } \\
\text { the ketogenic diet was compared } \\
\text { with rodent ketogenic diet }\end{array}$ & $\begin{array}{l}\text { There was a marked increase in the } \\
\text { weight of mice who were feeding } \\
\text { rodent ketogenic diet while a } \\
\text { marked decrease in the mice } \\
\text { occurred who were feeding on high } \\
\text { fats containing ketogenic diet }\end{array}$ & $\begin{array}{l}\text { This study was conducted on the } \\
\text { same types of mice but different } \\
\text { food groups were made in this } \\
\text { study }\end{array}$ \\
\hline Mitch, 1984 & $\begin{array}{l}\text { Number of patients: } \\
24\end{array}$ & $\begin{array}{l}\text { The patients were classified based } \\
\text { on their health conditions; the effect } \\
\text { of Keto supplements was observed } \\
\text { in the renal functions impaired } \\
\text { patients }\end{array}$ & $\begin{array}{l}10 \text { patients had marked decrease in } \\
\text { the creatinine level, in } 7 \text { patients, } \\
\text { creatinine level was maintained } \\
\text { below } 8 \mathrm{mg} \text { per decilitre }\end{array}$ & $\begin{array}{l}\text { This study was conducted on the } \\
\text { patients whose renal functions } \\
\text { were impaired and effect of keto } \\
\text { supplements were observed on } \\
\text { the health conditions of these } \\
\text { patients }\end{array}$ \\
\hline Cliff, 2018 & $\begin{array}{l}\text { This study was } \\
\text { conducted on } 28 \\
\text { healthy adults }\end{array}$ & $\begin{array}{l}\text { The comparison was made based on } \\
\text { their body conditions such as blood } \\
\text { glucose, mood disturbance }\end{array}$ & $\begin{array}{l}\text { It caused an increase in the } \\
\text { beta-hydroxybutyrate, but the effect } \\
\text { of MCT was unclear on mood. }\end{array}$ & $\begin{array}{l}\text { This study was conducted to } \\
\text { determine the effect of } \\
\text { medium-chain triglycerides } \\
\text { which are ketones in nature on } \\
\text { nutritional ketosis of body }\end{array}$ \\
\hline Volek, 2015 & $\begin{array}{l}\text { There were no groups } \\
\text { were made as it was } \\
\text { review based so } \\
\text { previous studies were } \\
\text { studied again and } \\
\text { their results were } \\
\text { compared }\end{array}$ & $\begin{array}{l}\text { The availability of carbohydrates is } \\
\text { reduced in the body is reduced } \\
\text { during exercise or sports-related } \\
\text { physical activity so lipid-containing } \\
\text { food can also be used as an alternate } \\
\text { of carbohydrates }\end{array}$ & $\begin{array}{l}\text { If the food is given containing to } \\
\text { ketone body and } \\
\text { beta-hydroxybutyrate then it } \\
\text { increases the mental and physical } \\
\text { and mental performance of humans } \\
\text { and the use of fats containing food } \\
\text { also increases the physical activity of } \\
\text { athletes }\end{array}$ & $\begin{array}{l}\text { The persons were shifted to fats } \\
\text { containing food who were } \\
\text { athletes or who were doing } \\
\text { sports-related physical activity }\end{array}$ \\
\hline
\end{tabular}




\section{Conclusions \& Recommendations}

Ultimately, it is important to note that the ketogenic-diet has caused debate, partially although traditional dietary education has, for years, illustrated the adverse effects of high overall including trans-fat intake. Polarization could also have emerged from the misunderstanding that ketogenic-diets need large intakes of animal products-provoking anxiety for all those who support seed-based diets for safety, moral or ecological purposes. Also, the ketogenic diet may be organic (featuring poultry and meat products) or vegetarian, with plant sources (e.g., avocado, almonds, nuts, almond, linseed, coconut oil), protein (e.g., yogurt, lupini, kimchi, tempeh, pumpkin, etc.) vegetables (non-starchy), and small quantities of low-sugar fruit, as exemplified by such versatility require the individualism of food preferences on a ketogenic-diet for obesity and diabetes. Taking into account the advantages as well as drawbacks, people who have kidney failure (such as those with type 2 diabetes) and persons with or at risk of cardiovascular disease including breast-feeding or pregnant women do not pursue ketogenic-diet. However, individuals of type 1 diabetes must not adopt the menu due to the current possibility of hypoglycaemia (low); also one who has already the gall-bladder replaced must skip it since the diet is too rich in fat. Losing weight, is the fact that requires a diet, plan and usually redesigns the pattern whatever individuals eat. And it might be worthwhile to try to shed obesity or have some of the medical problems that have been proven to improve. On precautionary side it must make sure to speak to the doctor on how the ketogenic-diet is right and to modify the food habits significantly. Although the diet is rooted in medication, its extensive use has been recent, and doctors are aware of the diet of keto.

Following are some recommendations in the context of ketogenic-diet effects:

1) It is essential not only to concentrate on consuming high-fat foods but also to provide a daily collection of fish, meat, veggies, berries, leafy greens required to have sufficient intake of nutrition, minerals, and vitamins A, B, etc. (magnesium, zinc, iron)-nutrients usually present in foods such as whole wheat that have been excluded from the diet.

2) Potential signs of acute creatine supplementation, which can last weeks to months, such as nausea, exhaustion, poor attitude, tiredness, indigestion, vomiting, and constipation in the brain, should be managed with medical check-up by specialists as well as nutritionists.

3) People who suffer from diabetes or inject insulin or oral hypoglycaemic drugs risk serious hypoglycaemia whether the medication is not correctly balanced until beginning the diet.

\section{Conflicts of Interest}

The authors declare no conflicts of interest regarding the publication of this paper.

\section{References}

[1] Ding, J., Xu, X., Wu, X., Huang, Z., Kong, G., Liu, J., Liu, Y., et al. (2019) Bone Loss and Biomechanical Reduction of Appendicular and Axial Bones under the Keto- 
genic Diet in Rats. Experimental and Therapeutic Medicine, 17, 2503-2510. https://doi.org/10.3892/etm.2019.7241

[2] Roberts, M.N., Wallace, M.A., Tomilov, A.A., Zhou, Z., Marcotte, G.R., Tran, D., Imai, D.M., et al. (2017) A Ketogenic Diet Extends Longevity and Health Span in Adult Mice. Cell Metabolism, 26, 539-546. https://doi.org/10.1016/j.cmet.2017.08.005

[3] Murphy, P., Likhodii, S.S., Hatamian, M. and Burnham, W.M. (2005) Effect of the Ketogenic Diet on the Activity Level of Wistar Rats. Paediatric Research, 57, 353-357. https://doi.org/10.1203/01.PDR.0000150804.18038.79

[4] Goldberg, E.L., Shchukina, I., Asher, J.L., Sidorov, S., Artyomov, M.N. and Dixit, V.D. (2020) Ketogenesis Activates Metabolically Protective $\gamma \delta$ T Cells in Visceral Adipose Tissue. Nature Metabolism, 2, 50-61. https://doi.org/10.1038/s42255-019-0160-6

[5] Enam, F. and Mansell, T.J. (2019) Prebiotics: Tools to Manipulate Gut Microbiome and Metabolome. Journal of Industrial Microbiology \& Biotechnology, 46, 1445-1459. https://doi.org/10.1007/s10295-019-02203-4

[6] Fan, Y., Hui-Min, M., Hu, G. and Fu-Li, L. (2018) Biosynthesis of Nervonic Acid and Perspectives for Its Production by Microalgae and Other Microorganisms. Applied Microbiology and Biotechnology, 102, 3027-3035. https://doi.org/10.1007/s00253-018-8859-y

[7] Qian, J., Li, K., Wang, P., Wang, C., Liu, J., Tian, X., Guan, W., et al. (2018) Unraveling Adsorption Behavior and Mechanism of Perfluorooctane Sulfonate (PFOS) on Aging Aquatic Sediments Contaminated with Engineered $\mathrm{Nano}^{-\mathrm{TiO}_{2}}$. Environmental Science and Pollution Research International, 25, 17878-17889. https://doi.org/10.1007/s11356-018-1984-4

[8] Marjana, R.S. and Franks, S.F. (2018) Efficacy of Curcumin for Age-Associated Cognitive Decline: A Narrative Review of Preclinical and Clinical Studies. GeroScience, 40, 73-95. https://doi.org/10.1007/s11357-018-0017-z

[9] Fomichev, Y.P. and Nikanova, L.A. (2017) Increasing of the Reproductive Properties of Boar Semen While Using Organic Iodine in Feeding. Russian Agricultural Sciences, 43, 419-422. https://doi.org/10.3103/S1068367417050056

[10] Lucarini, M., D’Evoli, L. and Lombardi-Boccia, G. (2020) Phytosterols and Phytosterol Oxides in Bronte's Pistachio (Pistacia vera L.) and in Processed Pistachio Products. European Food Research and Technology, 246, 307-314. https://doi.org/10.1007/s00217-019-03343-8

[11] Rückriemen, J., Hellwig, A., Schultes, S., Hellwig, M., Hahne, F. and Henle, T. (2018) Studies on the Influence of Dietary 3-Deoxyglucosone on the Urinary Excretion of 2-Keto-3-deoxygluconic Acid. European Food Research and Technology, 244, 1389-1396. https://doi.org/10.1007/s00217-018-3052-1

[12] Saini, R.K. and Young-Soo, K. (2019) Microbial Platforms to Produce Commercially Vital Carotenoids at Industrial Scale: An Updated Review of Critical Issues. Journal of Industrial Microbiology \& Biotechnology, 46, 657-674. https://doi.org/10.1007/s10295-018-2104-7

[13] Technavio (2019) Technavio Has Announced Its Latest Market Research Report Titled Global Keto Diet Market 2019-2023.

[14] Keto, J., Ventola, H., Jokelainen, J., Timonen, M., Linden, K., Ylisaukko-Oja, T., Auvinen, J., et al. (2017) Primary Health Care Utilization and Costs among Middle-Aged Smokers. The European Journal of Health Economics. HEPAC, 18, 351-360. https://doi.org/10.1007/s10198-016-0793-2 
[15] Innosa, D., Ianni, A., Palazzo, F., Martino, F., Bennato, F., Grotta, L. and Martino, G. (2019) High Temperature and Heating Effect on the Oxidative Stability of Dietary Cholesterol in Different Real Food Systems Arising from Eggs. European Food Research and Technology, 245, 1533-1538. https://doi.org/10.1007/s00217-019-03266-4

[16] Kennedy, A.R., Pissios, P., Otu, H., Xue, B., Asakura, K., Furukawa, N., Maratos-Flier, E., et al. (2007) A High-Fat, Ketogenic Diet Induces a Unique Metabolic State in Mice. American Journal of Physiology-Endocrinology and Metabolism, 292, E1724-E1739. https://doi.org/10.1152/ajpendo.00717.2006

[17] Duplisea, M.J., Wilson, E.K., Cheung, E.C., Parker, B.A., Carr, S.T., Ashby, C.K., Thomson, D.M., et al. (2017) Effects of Ketogenic Diet in Young Adult and Old Rats. The FASEB Journal, 31, lb724.

[18] Bansal, A., Rashid, C., Xin, F., Li, C., Polyak, E., Duemler, A., Simmons, R.A., et al. (2017) Sex- and Dose-Specific Effects of Maternal Bisphenol A Exposure on Pancreatic Islets of First- and Second-Generation Adult Mice Offspring. Environmental Health Perspectives, 125, Article ID: 097022. https://doi.org/10.1289/EHP1674

[19] Jeszka-Skowron, M., Oszust, K., Zgoła-Grześkowiak, A. and Frąc, M. (2018) Quality Assessment of Goji Fruits, Cranberries, and Raisins Using Selected Markers. European Food Research and Technology, 244, 2159-2168. https://doi.org/10.1007/s00217-018-3125-1

[20] Abdul-Hamid, N., Mediani, A., Maulidiani, M., Shadid, K., Ismail, I.S., Abas, F. and Lajis, N.H. (2018) Metabolite Characterization of Different Palm Date Varieties and the Correlation with Their NO Inhibitory Activity, Texture, and Sweetness. Journal of Food Science and Technology, 55, 1541-1551. https://doi.org/10.1007/s13197-018-3073-6

[21] Marcone, G.L., Rosini, E., Crespi, E. and Pollegioni, L. (2020) D-Amino Acids in Foods. Applied Microbiology and Biotechnology, 104, 555-574. https://doi.org/10.1007/s00253-019-10264-9

[22] Harder, A.M., Ardren, W.R., Evans, A.N., Futia, M.H., Kraft, C.E., Marsden, J.E., Christie, M.R., et al. (2018) Thiamine Deficiency in Fishes: Causes, Consequences, and Potential Solutions. Reviews in Fish Biology and Fisheries, 28, 865-886. https://doi.org/10.1007/s11160-018-9538-x

[23] Pollmann, H., Breitenbach, J. and Sandmann, G. (2017) Engineering of the Carotenoid Pathway in Xanthophyllomyces Dendrorhous Leading to the Synthesis of Zeaxanthin. Applied Microbiology and Biotechnology, 101, 103-111. https://doi.org/10.1007/s00253-016-7769-0

[24] Seth, V.D., Oubre, C. and Boopathy, R. (2019) Carbon Ecology of Termite Gut and Phenol Degradation by a Bacterium Isolated from the Gut of Termite. Journal of Industrial Microbiology \& Biotechnology, 46, 1265-1271. https://doi.org/10.1007/s10295-019-02183-5

[25] Elia, A.C., Magara, G., Righetti, M., Dörr, A.J., Martin, Scanzio, T., Prearo, M., et al. (2017) Oxidative Stress and Related Biomarkers in Cupric and Cuprous Chloride-Treated Rainbow Trout. Environmental Science and Pollution Research International, 24, 10205-10219. https://doi.org/10.1007/s11356-017-8651-Z

[26] Shubina, V.S. and Shatalin, Y.V. (2017) Antioxidant and Iron-Chelating Properties of Taxifolin and Its Condensation Product with Glyoxylic Acid. Journal of Food Science and Technology, 54, 1467-1475. https://doi.org/10.1007/s13197-017-2573-0 